\title{
EPLEY'S MANOEUVRE IN THE TREATMENT OF BPPV - OUR EXPERIENCE
}

\author{
C. E. Jacob ${ }^{1}$, Sajeev George M²
}

${ }^{1}$ Associate Professor, Department of ENT, M.O.S.C Medical College, Kolenchery, Kerala.

2 Professor and HOD, Department of ENT, M.O.S.C Medical College, Kolenchery, Kerala.

\begin{tabular}{l}
\hline ABSTRACT \\
BACKGROUND \\
Posterior Canal Benign Paroxysmal Positional Vertigo (PC-BPPV) is the commonest cause of peripheral vertigo in clinical practice. \\
Diagnosis is by Dix-Hallpike testing. Treatment is instituted by Epley's manoeuvre. We have studied a series of BPPV cases from \\
our ENT outpatient.
\end{tabular}

\section{MATERIALS AND METHODS}

Retrospective analysis of 19 outpatient records of 2016 was done. Only vertigo patients with nystagmus induced by Dix-Hallpike testing were included in the study. The efficacy of Epley's manoeuvre administered was analysed.

\section{RESULTS}

The manoeuvre as such has a 100 percent success rate, but 2 patients had a recurrence of symptoms after 3 months and 4 months respectively.

\section{CONCLUSION}

Our experience with the success of Epley's manoeuvre, in the short term, has been very promising. Also, this comes at no extra cost to the patient.

\section{KEYWORDS}

BPPV, Epley's Manoeuvre.

HOW TO CITE THIS ARTICLE: Jacob CE, George SM. Epley's manoeuvre in the treatment of BPPV - our experience. J. Evolution Med. Dent. Sci. 2017;6(1):4-6, DOI: 10.14260/Jemds/2017/2

\section{BACKGROUND}

The disorder called BPPV was described first by Barany in 1921. He noted the vertigo and the vertical and torsional components of the nystagmus. Dix and Hallpike in 1952, described their manoeuvre to elicit the classical pattern of nystagmus. ${ }^{1}$ They correctly identified the offending labyrinth. The accepted theory of causation is Canalithiasis. Calcium debris from the utricle enter the dependant part of the semicircular canals - which is posterior canal in most cases.

Once the offending labyrinth is identified on Dix-Hallpike test, PC-BPPV is treated using particle repositioning manoeuvre - that is Epley's manoeuvre.2,3 The culprit calcium debris is guided to re-enter the utricle by the aid of gravity. Though usually idiopathic, BPPV may be secondary to head injury, ear surgery like stapedectomy or cochlear implant surgery. Patient should be cooperative, because improper performance of Epley's manoeuvre and secondary BPPV may affect the initial treatment. ${ }^{4}$ The effect of Epley's manoeuvre in the treatment of positional vertigo is strongest in the first month. 5

In intractable cases, surgical treatment may be resorted by posterior semicircular canal occlusion. BPPV has an estimated prevalence of $2.4 \%$ in the adult population. The

Financial or Other, Competing Interest: None.

Submission 12-12-2016, Peer Review 25-12-2016,

Acceptance 27-12-2016, Published 02-01-2017.

Corresponding Author:

Dr. C. E. Jacob,

Associate Professor,

Department of E.N.T, M.O.S.C Medical College,

Kolenchery, Kerala-682311.

E-mail: jacobchundamannil68@gmail.com

DOI: $10.14260 /$ jemds $/ 2017 / 2$ commonest patient age group is between 50 and 70 years. Older patients run the risk of falls, hip fractures and so on and as a result higher hospital expenses in addition to affecting the quality of life. There are reports of BPPV developing after intense physical activity like swimming, yoga, running on pavement, working underneath objects like cars, repeatedly reaching high objects like in ceiling painters. Also in intense aerobic exercise, running on treadmill. In children diagnosis of BPPV was related to domestic injuries, school injuries, sports injuries and dental care. However, in recurrent cases there is usually a family history of migraine.

Migraine being more common in females, BPPV also is more prevalent in female patients. Frequent recurrence of vertigo in otherwise healthy young adults should bring about suspicion of migraine-associated vertigo.

\section{MATERIALS AND METHODS \\ Diagnosis}

BPPV was diagnosed based on patient symptoms - true vertigo induced by specific head movements (may or may not be accompanied by nausea or vomiting).

This was confirmed by a positive Dix-Hallpike manoeuvre - nystagmus was the hallmark. Induced by head turn to the offending side, lasts around few seconds only, fatigues off on repeating the test.

\section{Dix-Hallpike Test (Procedure)}

Absolute contraindications include fractured odontoid peg, recent cervical spine fracture, atlanto-axial subluxation, cervical disc prolapse, vertebrobasilar insufficiency that is verified, recent neck trauma that restricts torsional movement. 
We should be cautious in carotid sinus syncope, severe back pain, recent stroke, coronary bypass within 3 months, severe neck pain, recent neck surgery, cervical myelopathy, severe back pain, severe orthopnoea. The test should be performed using direct observation of eye movements and with optic fixation. Frenzel glasses or Videonystagmography (VNG) can be used to aid in characterising unusual nystagmus. Explain to the patient that he may experience some dizziness, but it is likely to be short-lived. Sit the patient on the couch such that when lying down shoulders will be level with the end of the couch. If history is suggestive of BPPV, start with the side that is least suspected.

Turn the patient head $45^{\circ}$ towards the test ear, holding head with both your hands. Patient should be instructed to fix his eyes on a point directly in front of him. Observe the eyes, noting the presence of any nystagmus.

Instruct the patient that on the count of 3 , you will bring his torso and head back quickly so head will be over the end of the couch. He must keep the eyes open even if he feels dizzy, because observation of eyes is important. Next sit him up on the count of 3 , maintaining the head at $45^{\circ}$ rotation, observe for nystagmus. If no nystagmus, after a short break repeat test on the other side. If nystagmus was observed, test should be observed till nystagmus stops. Note the direction, latency and duration of the nystagmus.

\section{Treatment}

\section{Procedure of Epley's Manoeuvre -}

This technique developed by Epley is effective in posterior canal BPPV (PC - BPPV).

First Step - BPPV is diagnosed by placing the patient's head in the Dix-Hallpike position, which elicits the nystagmus and vertigo. (The affected side posterior canal is in the earth vertical plane). Let the initial nystagmus settle.

Second Step - Now the head is turned $180^{\circ}$ (Then wait for nystagmus to settle) - till the offending ear is up.

Third Step - Then patient is brought to upright sitting position. Let the nystagmus settle.

Repeat the manoeuvre till no more nystagmus can be elicited. Gravity is the stimulus that moves the particles within the semicircular canal. Some physicians use a handheld vibrator to be kept over the mastoid to facilitate this movement. (We did not use this in our series).

\section{RESULTS}

The authors describe a series of 19 patients seen in the ENT outpatient in 2016. Theirs is a tertiary level referral hospital.

Age - Patients were aged 30 to 75.

Mean Age - 51.9 years.

\begin{tabular}{|c|c|c|c|c|c|}
\hline $\begin{array}{c}\text { Sl. } \\
\text { No. }\end{array}$ & $\begin{array}{c}\text { Age } \\
\text { (Years) }\end{array}$ & $\begin{array}{c}\text { Sex } \\
\text { (M/F) }\end{array}$ & $\begin{array}{c}\text { Side } \\
\text { Affected }\end{array}$ & $\begin{array}{c}\text { No. of } \\
\text { Sittings } \\
\text { of Epley's } \\
\text { Needed }\end{array}$ & Recurrence \\
\hline 1 & 58 & F & Right & 1 & Nil \\
\hline 2 & 54 & F & Right & 1 & Nil \\
\hline 3 & 51 & F & Right & 1 & $\begin{array}{c}\text { Yes } \\
\text { (3 Months })\end{array}$ \\
\hline 4 & 52 & F & Left & 1 & Nil \\
\hline
\end{tabular}

\begin{tabular}{|c|c|c|c|c|c|}
\hline 5 & 41 & M & Right & 3 & Nil \\
\hline 6 & 30 & F & Left & 1 & Nil \\
\hline 7 & 48 & M & Right & 1 & Nil \\
\hline 8 & 42 & F & Left & 1 & Nil \\
\hline 9 & 48 & F & Right & 1 & Nil \\
\hline 10 & 62 & F & Right & 1 & Nil \\
\hline 11 & 60 & M & Right & 1 & Nil \\
\hline 12 & 75 & M & Right & 1 & Nil \\
\hline 13 & 60 & M & Right & 1 & Nil \\
\hline 14 & 46 & F & Right & 1 & Nil \\
\hline 15 & 36 & F & Right & 1 & Nil \\
\hline 16 & 45 & M & Left & 2 & Nil \\
\hline 17 & 60 & M & Right & 1 & Nil \\
\hline 18 & 55 & F & Left & 1 & Nil \\
\hline 19 & 64 & M & Right & 2 & Yes \\
& \multicolumn{7}{|c|}{ Table 1. Data of Patients in the Study } \\
\hline
\end{tabular}

Sex - There were 11 females (57.9\%) and 8 males (42.1\%).

\section{Offending Side}

The posterior semicircular canal on the right was the culprit in 14 cases (73.7\%), left side in remaining 5 cases (26.3\%).

\section{Success Achieved by Epley's Manoeuvre}

Success in terms of absence of nystagmus on repeat DixHallpike testing was achieved in all the 19 patients in this series $(100 \%)$. As seen in the past, our study also shows effective and quick resolution of symptoms in treating BPPV. 6 Only one sitting Epley's manoeuvre was needed to achieve negative Dix-Hallpike in 16 out of 19 cases (84.2\%) - i.e. negative in the second sitting itself. Two sittings were needed for negativity to be achieved in 2 patients $(10.5 \%)$. Only in one case $(5.3 \%)$, he required 3 sittings. (Negative only by the $4^{\text {th }}$ sitting.)

This 41-year-old male patient had severe Diabetic retinopathy, which probably compromised his ocular component of habituation. So $100 \%$ success rate was appreciated with Epley's in the short-term follow-up in this series.

\section{Recurrence of Symptoms}

2 out of our 19 (10.5\%) patients had recurrence of giddiness at 3 and 4 months respectively. Both patients had giddiness, but no nystagmus with Dix-Hallpike. Symptoms resolved with vestibular habituation exercises.

\section{DISCUSSION}

Posterior canal Benign Paroxysmal Positional Vertigo (PC BPPV) is a frequently encountered clinical situation. BPPV commonly has been cited to occur mostly between $50 \mathrm{~s}$ to $70 \mathrm{~s}$. In our study, patients were aged ranging from 30 to 75 . (Mean age 51.9). The success of Epley's manoeuvre in treating PC-BPPV has been proven in a double-blind randomised study, wherein the manoeuvre was compared with a sham procedure. Epley's clearly provided effective and rapid resolution of symptoms in this study. ${ }^{6}$

Patient age less than 40 years and duration of attacks of vertigo less than 3 years may be a good prognostic factors according to one study. ${ }^{7}$ This was not really applicable in our study, as there were only 2 patients below 40 years of age. 
In a study by Roa et al, treatment of BPPV by Epley's manoeuvre was compared with vestibular habituation training. Here, Epley's greatly reduces the time required to attain normalcy - significant differences between the two arms occurring on completion of seven days of treatment. 8

As far as effectiveness of Epley's manoeuvre is concerned, we got $100 \%$ success following the procedure in the short term. That is, all 19 patients had negative Dix-Hallpike post procedure. Regarding recurrences, 2 patients (10.5\%) - one female aged 51 and the other male aged 64 had giddiness again at 3 and 4 months respectively. Dix-Hallpike being negative, their symptoms resolved with vestibular habituation exercises itself.

\section{CONCLUSION}

Epley's manoeuvre as a treatment tool in PC-BPPV has $100 \%$ success rate in the short-term followup. Patients are relieved of their distressing symptom and are drug-free. There is no added treatment cost also for this effective method. So we strongly recommend Dix-Hallpike test for the diagnosis and Epley's manoeuvre for treatment of the PC-BPPV patient, if they are co-operative.

\section{REFERENCES}

[1] Dix MR, Hallpike CS. The pathology, symptomatology and diagnosis of certain common disorders of the vestibular system. Ann Otol Rhinol Laryngol 1952;61(4):987-1016.
[2] Epley JM. The canalith repositioning procedure: for treatment of benign paroxysmal positional vertigo. Otolaryngol Head Neck Surg 1991;107:399-404.

[3] Furman JM, Cass SP. Benign paroxysmal positional vertigo. N Engl J Med 1999;341(21):1590-6.

[4] Korres S, Balatsouras DG, Ferekidis E. Prognosis of patients with benign paroxysmal positionl vertigo treated with repositioning manoeuvres. J Laryngol Otol 2006;120(7):528-33.

[5] Woodworth BA, Gillespie MB, Lambert PR. The canalith repositioning procedure for benign positional vertigo: a meta-analysis. Laryngoscope 2004;114(7):1143-6.

[6] von Brevern M, Seelig T, Radtke A, et al. Short term efficacy of Epley's manoeuvre: a double blind randomized trial. J Neurol Neurosurg Psychiatry 2006;77(8):980-2.

[7] Rashad UM. Long term follow up after Epley's manoeuvre in patients with benign paroxysmal positional vertigo. J Laryngol Otol 2009;123(1):69-74.

[8] Roa Castro FM, Duran de Alba LM, Roa Castro VH. Experience with Epley's manoeuvre and vestibular habituation training in benign paroxysmal positional vertigo. Acta Otorhino Esp 2008;59(3):91-5. 